\title{
"Elas tomaram o poder!": quando as leitoras tornaram-se autoras. Considerações sobre o leitor e a recepção dos textos literários nos dias atuais
}

\author{
Amanda Crispim Ferreira \\ Mestranda Estudos Literários / UFMG
}

\begin{abstract}
RESUMO
O presente artigo pretende analisar o papel do leitor na crítica literária moderna, buscando refletir sobre a experiência de um leitor específico: a mulher afro-brasileira. Para esta análise, faremos uma comparação entre os textos Clara dos Anjos, de Lima Barreto, e “Guarde segredo”, de Esmeralda Ribeiro.
\end{abstract}

\section{PALAVRAS-CHAVE}

Leitora, mulher afro-brasileira, Clara dos Anjos, "Guarde segredo”

O último século presenciou o desenvolvimento da ciência que busca avaliar os textos literários, ou seja, a crítica literária. Dentre as suas diversas formas de manifestação que surgiram no século 20, podemos encontrar uma, que, diferentemente das suas antecessoras, sua preocupação não está calcada somente na linguagem ou no texto, mas no leitor e na sua experiência de leitura, tornando-se seu objeto. A essa nova forma de crítica podemos chamar de "Estética da Recepção":

A teoria da recepção examina o papel do leitor na literatura e, como tal é algo bastante novo. De forma muito sumária, poderíamos periodizar a história da moderna teoria literária em três fases: uma preocupação com o autor (romantismo e século XIX); uma preocupação exclusiva com o texto (Nova Crítica) e uma acentuada transferência da atenção para o leitor, nos últimos anos. (...) Estes textos não existem nas prateleiras das estantes: são processos de significação que só se materializam na prática da leitura. Para que a literatura aconteça, o leitor é tão vital quanto o autor. ${ }^{1}$

\footnotetext{
${ }^{1}$ EAGLETON. Teoria da literatura: uma introdução[0], p.113.
} 
Pensar o leitor como peça fundamental para a compreensão do texto literário, é também entender o texto desvencilhado da ideia de que ele é a única fonte de interpretação da obra, assim como pensar a linguagem também desvencilhada da ideia de que ela é única capaz de traduzir todas as intenções do falante. A ascensão do leitor culmina também na queda ou “morte” do autor, ideia divulgada pelo francês Roland Barthes, na década de 1980, com o texto “A morte do autor”, publicado no livro O rumor da língua em 1984. Para Barthes, o autor, “morreu”, enquanto entidade “detentora do sentido” do texto que escreveu:

Embora seja o produtor do texto, ou seja, aquele que articula lingüisticamente idéias, sentimentos, posições, entende-se hoje, que ele não controla o(s) sentido (s) que sua produção pode suscitar. O autor não é mais considerado o "dono" do sentido do texto nem pelos leitores, nem pelos responsáveis por editar ou transformar um original em objeto que vai ser lido. $^{2}$

Assim, a Estética da Recepção propõe uma nova forma de avaliar os textos literários, a partir da experiência do leitor:

Ora, se o texto já não diz tudo, nem seu autor é o dono de um sentido para ele, o leitor tem sido considerado peça fundamental no processo de leitura. Seja individualmente, seja coletivamente, o leitor é a instância responsável por atribuir sentido àquilo que lê. A materialidade do texto, o preto no branco do papel só se transformam em sentido quando alguém resolve ler. E, assim, os textos são lidos sempre de acordo com uma dada experiência de vida, de leituras anteriores, e num certo momento histórico, transformando o leitor em instância fundamental na construção do processo de significação desencadeado pela leitura de textos. ${ }^{3}$

Sabemos que a relação leitor-texto é evidente, porém a crítica literária só passou a olhá-la de forma sistemática a partir dos anos 1960, com os estudos da Estética da Recepção. ${ }^{4}$ Vários autores, da chamada moderna teoria literária, dedicaram-se a pensar a Literatura a partir do enfoque da experiência do leitor, dos quais podemos destacar Roland Barthes, Hans Robert Jauss, Umberto Eco, Wolfgang Iser, Stanley Fish, e mais atualmente, Roger Chartier. Acredita-se que o maior representante e também criador da teoria “Estética da Recepção" seja Hans Robert Jauss. ${ }^{5}$ Sendo assim, ateremos-nos mais as suas ideias neste artigo.

Considerando o pensamento de Jauss, propomo-nos neste texto a pensar a figura do leitor em nosso quadro literário atual. Porém, o este leitor não é um leitor qualquer, e sim um

\footnotetext{
${ }^{2}$ ZAPPONE. Estética da recepção[0], p.189.

${ }^{3}$ ZAPPONE. Estética da recepção[0], p.189.

${ }^{4}$ ZAPPONE. Estética da recepção[0], p.189.

${ }^{5}$ ZAPPONE. Estética da recepção[0], p. 191.
} 
leitor específico, de um público que tem se formado nos últimos anos: a mulher negra brasileira. Para esta reflexão, faremos uma análise comparativa entre o romance Clara dos Anjos, do escritor brasileiro Lima Barreto, e o conto "Guarde segredo", da escritora Esmeralda Ribeiro. Tais textos foram escolhidos porque o segundo é uma reescritura do primeiro, tornando-se exemplo claro para pensarmos sobre a figura do leitor e a recepção dos textos. Outro motivo é que ambos os textos abordam a questão da representação da mulher negra na Literatura: o primeiro , Clara dos Anjos,é a visão de um homem que viveu entre o final do século 19 e o início do 20 e pensa a mulher negra na sociedade brasileira dessa época. Já o segundo, é um texto escrito por uma mulher negra, contemporânea, que leu o romance de Lima Barreto e, diante das colocações de seu antecessor, reescreve-o, apropriando-se dos personagens e do tema do romance, porém com o intuito de representar a mulher negra na sociedade brasileira contemporânea por meio da voz da própria mulher negra brasileira contemporânea.

Nesse sentido, analisaremos os textos citados, embasados pela teoria da Estética da Recepção, buscando refletir sobre o papel do leitor, mais precisamente a leitora afrobrasileira.

\section{CLARA DOS ANJOS E "GUARDE SEGREDO": DOIS OLHARES SOBRE UMA MESMA QUESTÃO}

Clara dos Anjos foi o último romance de Lima Barreto a ser publicado; apesar de começar a ser escrito em 1904, ${ }^{6}$ início de sua carreira, só chegou ao conhecimento do público em 1948, após a sua morte, em 1922. A história de Clara, uma moça negra e pobre que é seduzida, enganada e abandonada grávida, por Cassi Jones, o moço rico e branco, ficou conhecida como o romance inacabado de Lima Barreto, pois, segundo Maria do Carmo Lanna Figueiredo: "Clara dos Anjos é o menos fidedigno dos textos de romances do autor, por haver-se extraviado o original manuscrito e porque sua primeira edição, em folhetins da Revista Souza Cruz, não mereceu boa revisão.”7 Ainda segundo Figueiredo, vários rascunhos mostram que a obra pretendia ser mais ampla e abordar mais temas, como a realidade de outras mulheres do mesmo meio e cor, e não restringir-se apenas à história da protagonista, como aponta a dedicatória do autor -“á memória de minha mãe” - e sua epígrafe inicial retirada das Histórias do Brasil, de João Ribeiro: “Alguns as desposavam (as índias); outros,

\footnotetext{
${ }^{6}$ BOSI. História concisa da literatura brasileira, p. 321.

${ }^{7}$ HOUAISS citado por FIGUEIREDO. A atualidade da obra de Lima Barreto[0], p. 151.
} 
quase todos, abusavam da inocência delas, como ainda hoje das mestiças, reduzindo-as por igual a concubinas e escravas.” ${ }^{8}$ Marcos Hidemi de Lima ${ }^{9}$ também aborda esse tema:

Pelo longo tempo que o escritor dedicou a essa história, é possível inferir que este romance tivesse uma grande representatividade não só para sua produção literária, bem como para exorcizar os fantasmas do preconceito que se debatiam no seu íntimo. Se tivesse sido levado a termo, como explicita em algumas páginas do Diário íntimo, de fato a obra seria capaz de proporcionar um quadro da sociedade brasileira, desde meados do século XIX até as primeiras décadas pós-abolição. No entanto, mesmo que Lima Barreto tenha mantido a estrutura fundamental da história, que é o "de uma moça pobre e mulata seduzida por um valdevinos de boa família”, (BARRETO: 1948, p. 14) segundo Lúcia Miguel Pereira, percebe-se que suas variadas versões de Clara dos Anjos apontam para a frustração de possivelmente não ter feito seu grande romance sobre o dilema da mulher afro-descendente diante do preconceito racial, da exploração sexual e da miséria socioeconômica.

Assim, por conta desse caráter incompleto e outras características, como o excessivo traço confessional, a concepção maniqueísta e pessimista do mundo, linguagem coloquial, o romance foi avaliado pela crítica da época como o pior da bibliografia do autor. ${ }^{10}$

O romance em questão, assim como os demais textos de sua bibliografia, tem como característica principal a denúncia da sociedade brasileira do início do século 20, abordando temas como o preconceito étnico, causa de segregação e, consequentemente, a não inserção da população negra nessa sociedade, além da população pobre, que tinha o mesmo destino. Pobre e negro, Lima Barreto se encaixava exatamente nesse grupo de excluídos, e por isso, é claro em seus textos o lugar de onde fala o narrador de sua obra, lugar que o próprio autor fez questão de evidenciar, por meio de narradores em $1^{\text {a }}$ pessoa ou personagens em que se pode lembrar do autor. Para o primeiro caso, podemos citar o exemplo do narrador/protagonista de Recordações do escrivão Isaías Caminha, texto que a crítica acredita ser autobiográfico, ou seja, o escrivão seria o próprio Lima Barreto, devido a personalidade do protagonista, que se assemelha à do escritor, o preconceito que o protagonista sofre por ser negro e a suspeita de que o livro que o protagonista escrevia durante o enredo era Clara dos Anjos. Para o segundo caso, podemos citar como exemplo a personagem Leonardo Flores, de Clara dos Anjos, que é um poeta que tivera momentos de felicidade, mas que tem sua carreira destruída pelo vício do álcool. Por meio dessa personagem também percebemos um retrato das ideias e pensamentos do próprio autor a respeito de questões como a arte e a figura do poeta na sociedade da época.

\footnotetext{
${ }^{8}$ FIGUEIREDO. A atualidade da obra de Lima Barreto[0], p. 151.

${ }^{9}$ LIMA. Pobre, mulata, mulher: a estigmatização de Clara dos Anjos.

${ }^{10}$ FIGUEIREDO. A atualidade da obra de Lima Barreto[0], p. 152.
} 
Diferentemente de seu antecessor Machado de Assis, que usava da estratégia de escritor "caramujo", ou seja, aquele que se esconde atrás do outro para denunciar o preconceito étnico na sociedade brasileira, visto que seus textos eram publicados nos jornais lidos pelos brancos -, tal estratégia era necessária para que não sofresse a censura da imprensa administrada pela elite -, Lima Barreto utiliza-se de um tom agressivo e “afiado” na escrita, refletindo a mágoa que tem da sociedade por discriminá-lo devido a sua condição. Tal estilo de escrita o levou para o limbo do cânone literário durante anos, já que sua obra atacava explicitamente o público leitor da época.

Retomando Jauss e as ideias da Estética da Recepção, podemos pensar que a obra barretiana não correspondia ao horizonte de expectativa da época, que, além de afastá-lo do horizonte de expectativa do público - leitores e crítica da época -, chegava a contrariá-lo. Nesse sentido, não era de interesse consumir o texto de Lima Barreto, que, após três tentativas frustradas de entrar para a Academia Brasileira de Letras, morreu doente, pobre e sem conhecer o sucesso.

Anos mais tarde, sua bibliografia é desengavetada, e finalmente a crítica, envolvida pelas teorias pós-coloniais e estudos de alteridade que começaram a ganhar espaço no final do século 20, dispõe-se a revê-la sua obra com mais profundidade e compreender que sua escrita realmente não correspondia ao horizonte de expectativa da época, mas o superava, propondo um novo horizonte. Hoje, com o novo quadro literário que se tem apresentado, em que textos denominados afro-brasileiros, indígenas, femininos ou homoeróticos, que tem por objetivo dar voz às minorias, têm começado a emergir, percebe-se que a obra de Lima Barreto foi a precursora dessa nova proposta de Literatura. Sobre essa mudança na recepção de uma obra, podemos apontar a visão de Jauss, no texto "Estética da recepção": ${ }^{11}$

Como se vê, para Jauss, o lugar de uma obra na série literária não pode ser determinado apenas em razão de sua recepção inicial, portanto baseando-se apenas no contraste entre o novo e o velho no momento da sua aparição. Essa função ou lugar depende, também, da história das recepções de um texto. Explica que, às vezes, o valor de uma obra não é percebido no momento de sua recepção inicial, já que a distância estética entre o horizonte de expectativa da obra e do público é muito grande e, talvez, seja necessário um longo processo de recepção para que a obra venha a ser compreendida. Logo, para Jauss, a história literária baseada no critério recepcional não é um processo linear, seqüencial, de obras literárias, mas um conjunto aberto de possibilidades, já que sentidos novos podem ser vistos em textos antigos, o que permite um constante reavaliar dos textos literários.

\footnotetext{
${ }^{11}$ ZAPPONE. Estética da recepção[0], p. 197. (grifo do autor)
} 
É nesse novo cenário que encontramos o conto "Guarde segredo", de Esmeralda Ribeiro, publicado em 1991 no 14 volume da coleção Cadernos Negros. O texto dialoga com o romance de Lima Barreto, pois conta a mesma história, a de uma jovem que, traída pelo namorado e humilhada por sua futura sogra, decide matá-lo a facadas. Em um primeiro momento, os dois textos parecem não ter muita coisa em comum, a não ser pelo namorado infiel e pela sogra arrogante. O diálogo se dá, contudo, quando o narrador do conto, em primeira pessoa, nos apresenta o nome de seu namorado: Cassi Jones, que é o mesmo nome do namorado da protgonista de Clara dos Anjos. A semelhança vai se tornando mais evidente quando o narrador descreve as características físicas e psicológicas de Cassi Jones, levando o leitor, que já tenha lido Clara dos Anjos, a lembrar-se da personagem de Lima Barreto. Tal fato provavelmente assusta os leitores, quando chegam a um determinado momento da narrativa e percebem um fim diferente e inesperado. Acostumados com o drama de Clara, apresentado há quase meio século para o público brasileiro, o conto de Esmeralda Ribeiro traz uma reviravolta da protagonista, que não aceita a humilhação sofrida e reage, assassinando o namorado.

Diante disso, percebemos que Esmeralda Ribeiro faz uma releitura do romance do seu antecessor, e, incomodada com o enredo proposto por Lima Barreto, propõe uma reescritura ${ }^{12}$ do mesmo. Sobre a participação do leitor no ato da escrita, podemos citar o comentário de Eagleton $^{13}$ acerca da visão do crítico americano Stanley Fish: “O verdadeiro escritor é o leitor: descontente com a mera co-participação iseriana na empresa literária, os leitores agora derrubam os patrões e se instalam no poder." ${ }^{14}$ Nesse sentido, o que propomos neste artigo é refletir sobre este ato de reescritura de Esmeralda Ribeiro. Por que reescrever Clara dos Anjos?

Sabemos que os dois autores abordam a questão racial e social; contudo, o que impulsiona e modifica o discurso de Esmeralda Ribeiro é a questão de gênero, ou seja, o fato de ela ser uma mulher e escrever a partir de uma perspectiva feminina - aspecto que não foi abordado em Lima Barreto. Quando o autor fez a denúncia da situação em que viviam os

${ }^{12}$ Conceito de releitura e reescritura proposto por Thomas Bonnici (BONNICI. Teoria e crítica póscolonialistas[0], p. 269-272.) Em que o primeiro consiste "numa estratégia para ler textos literários ou não-literários e, dessa maneira garimpar suas implicações imperialistas e trazer a tona o processo colonial.” (BONNICI. Teoria e crítica pós-colonialistas[0], p. 269) e o segundo consiste em "selecionar um texto canônico da metrópole, e através de recursos de paródia , produzir uma nova obra, escrita do ponto de vista da ex-colônia." (BONNICI. Teoria e crítica póscolonialistas[0], p. 271.)

${ }^{13}$ EAGLETON. Teoria da literatura: uma introdução[0].

${ }^{14}$ FISH citado por EAGLETON. Teoria da literatura: uma introdução[0], p. 129. 
negros no início do século 20, ele só abordou uma visão do preconceito, ou seja , a racial. porém, hoje, falar do preconceito racial sem abordar a questão do gênero, dá à análise uma “visão caolha”, visto que a luta pelo direito das mulheres negras tem ganhado espaço nos últimos anos.

Ao lermos o conto, fica claro o lugar de onde fala o narrador, uma mulher, negra, situada no final do século 20, que não aceita o destino que Lima Barreto dá à sua protagonista, que representa várias mulheres negras da época, e reescreve um novo destino para sua personagem. Assim, o conto transmite a reação que teve uma mulher negra brasileira desse tempo, quando leu o texto de Lima Barreto. Uma mulher que fala em nome de várias outras Mulheres que se dão o direito de serem sujeitos de sua história e reescrevê-las. Tal abordagem é profunda, porque trata de uma questão que vem sendo discutida nos últimos tempos: em que lugar se encaixa a militância da mulher negra? José Eugênio das Neves reflete sobre essa questão citando Bonnici em seu artigo "Esmeralda Ribeiro e Lima Barreto: um diálogo sem segredos": 15

Verifica-se então que a situação da mulher colonizada é pior do que a do homem na mesma situação, de vez que sofre uma dupla colonização, política e de gênero, complementando o pensamento do autor acima mencionado [Bonnici], acrescentamos que pode haver uma situação ainda mais trágica: uma tripla colonização, que se verifica no caso das mulheres afrodescendentes que vivem em países colonizados. Neste caso, além da dominação política e de gênero, verifica-se ainda outra ligada ao fator étnico.

Sueli Carneiro, militante negra brasileira, também aborda essa questão em seu artigo "Enegrecer o feminismo: a situação da mulher negra na América Latina a partir de uma perspectiva de gênero” e questiona: qual o lugar da mulher negra no movimento negro? Qual o lugar da mulher negra no movimento feminista?

Em geral, a unidade na luta das mulheres em nossas sociedades não depende apenas da nossa capacidade de superar as desigualdades geradas pela histórica hegemonia masculina, mas exige, também, a superação de ideologias complementares desse sistema de opressão, como é o caso do racismo. O racismo estabelece a inferioridade social dos segmentos negros da população em geral e das mulheres negras em particular, operando ademais como fator de divisão na luta das mulheres pelos privilégios que se instituem para as mulheres brancas.

Nessa perspectiva, a luta das mulheres negras contra a opressão de gênero e de raça vem desenhando novos contornos para a ação política feminista e

\footnotetext{
${ }^{15}$ NEVES. Esmeralda Ribeiro e Lima Barreto: um diálogo sem segredos, p. 49.
} 
anti-racista, enriquecendo tanto a discussão da questão racial, como a questão de gênero na sociedade brasileira. ${ }^{16}$

Nesse sentido, sabendo-se da situação da mulher negra brasileira atualmente, e da distância de mais de meio século entre os dois textos, podemos dizer que o conto é uma tentativa de retratar a mesma questão, ou seja, a mulher negra na sociedade brasileira, porém por meio de outro olhar, sob a ótica de quem sofreu e ainda sofre o preconceito. Sabemos que Lima Barreto sofreu por ser negro, contudo, como já nos mostraram as citações acima, ser homem negro e ser mulher negra, em nossa sociedade, não é a mesma coisa, já que a mulher é discriminada não somente por ser negra mas também por ser mulher.

O conto, escrito em forma de carta, apresenta um destinatário ou narratário, denominado apenas por "Prezada Senhora”. O remetente ou narrador, que não tem nome, é feminino. Essa é a primeira marca da mudança de perspectiva proposta por Esmeralda, um narrador feminino, ou seja, não é mais preciso um homem dar voz às mulheres, e destinado a um público também feminino. O anonimato das personagens, narradora e narratária, atentanos para a possível conclusão de que Esmeralda Ribeiro não as nomeia para atribuir estas funções de remetentes e destinatárias a todas as mulheres que se identificarem com a

16 “O artigo traz questionamentos interessantes como: Quando falamos do mito da fragilidade feminina, que justificou historicamente a proteção paternalista dos homens sobre as mulheres, de que mulheres estamos falando? Nós, mulheres negras, fazemos parte de um contingente de mulheres, provavelmente majoritário, que nunca reconheceram em si mesmas esse mito, porque nunca fomos tratadas como frágeis. Fazemos parte de um contingente de mulheres que trabalharam durante séculos como escravas nas lavouras ou nas ruas, como vendedoras, quituteiras, prostitutas... Mulheres que não entenderam nada quando as feministas disseram que as mulheres deveriam ganhar as ruas e trabalhar! Fazemos parte de um contingente de mulheres com identidade de objeto. Ontem, a serviço de frágeis sinhazinhas e de senhores de engenho tarados. Hoje, empregadas domésticas de mulheres liberadas e dondocas, ou de mulatas tipo exportação. Quando falamos em romper com o mito da rainha do lar, da musa idolatrada dos poetas, de que mulheres estamos falando? As mulheres negras fazem parte de um contingente de mulheres que não são rainhas de nada, que são retratadas como antimusas da sociedade brasileira, porque o modelo estético de mulher é a mulher branca. Quando falamos em garantir as mesmas oportunidades para homens e mulheres no mercado de trabalho, estamos garantindo emprego para que tipo de mulher? Fazemos parte de um contingente de mulheres para as quais os anúncios de emprego destacam a frase: 'Exige-se boa aparência.' Quando falamos que a mulher é um subproduto do homem, posto que foi feita da costela de Adão, de que mulher estamos falando? Fazemos parte de um contingente de mulheres originárias de uma cultura que não tem Adão. Originárias de uma cultura violada, folclorizada e marginalizada, tratada como coisa primitiva, coisa do diabo, esse também um alienígena para a nossa cultura. Fazemos parte de um contingente de mulheres ignoradas pelo sistema de saúde na sua especialidade, porque o mito da democracia racial presente em todas nós torna desnecessário o registro da cor dos pacientes nos formulários da rede pública, informação que seria indispensável para avaliarmos as condições de saúde das mulheres negras no Brasil, pois sabemos, por dados de outros países, que as mulheres brancas e negras apresentam diferenças significativas em termos de saúde.” (CARNEIRO. Enegrecer o feminismo: a situação da mulher negra na América Latina a partir de uma perspectiva de gênero, [s.p.].) 
narradora ou com a narratária desse conto. Eagleton também comentou sobre a questão do público, em seus escritos sobre a estética da recepção:

Todo leitor literário é construído a partir de um certo sentimento em relação ao seu público potencial, e inclui uma imagem daqueles a quem se destina: toda obra encerra em si mesma aquilo que Iser chama de um "leitor implícito"; inclui em todas as suas atitudes o tipo de publico que prevê. $\mathrm{O}$ “consumo”, tanto na produção literária como em qualquer outra, é parte do processo de produção. ${ }^{17}$

Logo no início do conto, a narradora nos revela, por meio da narratária, sua angústia, devido a tudo que aconteceu durante sua infância e adolescência, tempo em que morou com a vó Olívia, e ao mesmo tempo o desejo de “desabafar”, ou seja, contar a alguém tudo o que lhe aconteceu, já que no lugar onde vivia ninguém a conhecia. A protagonista inicia a narrativa descrevendo o local onde ficava a casa da avó. Não coincidentemente, o bairro era o Todos os Santos, situado no subúrbio do Rio de Janeiro, e a rua era a Major Mascarenhas, lugar onde Lima Barreto morou e escreveu Clara dos Anjos. Será que casa da vó Olívia era a casa onde Lima Barreto morou?

Misturar realidade e ficção é uma das características desse conto - um ato ousado de Esmeralda Ribeiro, que, como boa leitora de Lima Barreto, pensou em vários detalhes para essa releitura. Além do endereço não fictício da casa da avó da protagonista, outra personagem real aparece no conto, o próprio Lima Barreto, que é apresentado como um fantasma que acompanha toda a trajetória da protagonista, aparecendo ora no jardim da casa, ora em um dos quartos escrevendo na máquina de escrever, ora conversando com vó Olívia: "Brincava sozinha. Sozinha, não. Um homem sempre aparecia pra gente brincar. Como surgia, também sumia, de repente. Parecíamos velhos conhecidos. Quem é ele? - pensava.”18

O tom misterioso do conto reforça-se também pela figura da avó, que se caracterizava como uma mulher de poucas palavras, geniosa, firme e autoritária. Por várias vezes ela sumia e aparecia de repente, ou soltava frases misteriosas ou vazias que não sanavam completamente as dúvidas da neta. Questionada diante de suas atitudes, ela sempre se esquivava, procurando não responder:

Vovó guardava além de cacarecos, algum segredo, porque eram todos (os quartos da casa) trancados. Andava com o molho de chaves no bolso, não o largava nem para dormir. Eu achava essa atitude estranha, porém se a

\footnotetext{
${ }^{17}$ EAGLETON. Teoria da literatura: uma introdução[0], p. 127.

${ }^{18}$ RIBEIRO. Guarde segredo, p. 26.
} 
interrogasse, certamente ela diria "Vê se não me amola". Sempre dizia essa frase. ${ }^{19}$

À medida que se vai lendo o conto, vai-se tendo "pistas" que nos levam a crer que os dois personagens citados acima estão na terra somente para "corrigir” o final que Lima Barreto deu à Clara anos atrás. Tais figuras são as responsáveis pela educação da protagonista, visto que vai morar com avó ainda criança, e seus pais quase não a visitam, propondo uma educação diferente à dos pais de Clara dos Anjos, que a trancavam em casa e não a deixavam sair para nada, a não ser em companhia da mãe ou de Dona Margarida, uma viúva muito séria que morava na vizinhança e ensinava-lhe bordados e $\operatorname{costuras}^{20}$ e preparando-a para reagir também de forma diferente, quando o momento chegasse. A impressão que se tem, ao ler o conto, é que Lima Barreto também estava incomodado com sua versão da história e precisava redimir-se com Clara e todas as outras mulheres que se sentiram ofendidas. Assim, o enredo proposto por Esmeralda Ribeiro aponta os possíveis "erros" cometidos pelo autor e procura consertá-los. O caráter incompleto do romance Clara dos Anjos nos permite inferir tais hipóteses, que são possivelmente confirmadas pelas atitudes das personagens no conto. Não é à toa que a personagem de Lima Barreto aparece sempre escrevendo, como se fosse reescrevendo a história a partir das cenas que presenciava dessa nova protagonista. Assim, vai confirmando-se a ideia manifestada acima, de que estas personagens, Lima Barreto e Vó Olívia, fossem destinadas a terra somente para ajudar a nova Clara a cumprir sua missão de modificar o destino da primeira, pois, assim que a protagonista conta a eles que matou Cassi Jones e foge da polícia, ela nunca mais tem notícias dos dois:

Fui entrando, entrando e ouvi o Lima Barreto escrevendo á máquina. Conversavam e riam muito. Por um momento, juro tê-lo ouvido dizer: "Esperávamos por você. Entre.” Eu pensava: "Tudo esta acontecendo ao mesmo tempo.”

- Você matou Cassi Jones? - ele interrompeu meu devaneio.

- Matei - respondi. “como soube disso?”, interroguei-me.

- Bravo! Esse era o outro final que eu queria para o cafajeste do Cassi Jones.

O escritor tirou da máquina o papel, rasgou em pedacinhos e jogou no lixo. Olhou para vovó e disse: "Obrigado. Eternamente obrigado.” Então vovó Olívia falou aquilo: "Tinha que ser assim, minha neta”, e continuou: "Nós não devemos aceitar o destino com resignação." Fiquei parada, olhando para os dois. Vovó prosseguiu: "Não tive culpa, foi ele quem pediu pra voltar" (...) depois daquele dia, nunca mais voltei àquela casa. Nunca mais soube de vovó Olívia. ${ }^{21}$

\footnotetext{
${ }^{19}$ RIBEIRO. Guarde segredo, p. 25.

${ }^{20}$ BARRETO. Clara dos Anjos, p. 18.

${ }^{21}$ RIBEIRO. Guarde segredo, p. 29-30.
} 
O trecho acima confirma as hipóteses mencionadas no parágrafo anterior, principalmente quando a personagem Lima Barreto finalmente termina de escrever o texto após a chegada da protagonista com a notícia de ter matado Cassi Jones, ou seja, ter cumprido sua missão. Como a missão da protagonista já tinha sido cumprida, consequentemente a dele também, sendo assim, agradece à vó Olívia, por ter permitido a sua volta, abrigando-o novamente em sua casa, em sua máquina de escrever e inserindo-o em seu cotidiano e no cotidiano de sua neta, e provavelmente desaparece, com o sentimento de missão cumprida, de alma livre, como se antes seu espírito estivesse aprisionado por aquela responsabilidade de dar outro fim “ao cafajeste do Cassi Jones”.

A frase de vó Olívia - “Nós não devemos aceitar o destino com resignação”- vem opor-se claramente ao texto de Lima Barreto, mais precisamente a última frase do livro, que é o desabafo de Clara diante da constatação do destino futuro trágico que lhe aguardava, já que a sociedade não admitia mulheres solteiras grávidas na época: “Mamãe, mamãe - Que é minha filha? - Nós não somos nada nesta vida." ${ }^{22}$ Ao colocar essa frase no conto, Esmeralda justifica a ação de sua protagonista e também a sua atitude de reescrever Clara dos Anjos, pois não aceitar o destino com resignação é não submeter-se ao que o destino lhe reservou. O que o destino pode reservar a uma mulher negra, no início do século 20 ou nos tempos atuais? Nada. Como já disse Clara dos Anjos, tempos atrás. O que as mulheres negras são hoje, não é regalia do destino, mas fruto de sua própria luta para interferir e modificá-lo. As palavras da avó para a neta são como uma herança, já que consistem nas poucas coisas que a avó disse e uma das últimas coisas que disse antes da separação das duas. Percebe-se que era o ensinamento que a avó gostaria que permanecesse para ser transmitido às outras gerações.

Por meio das palavras de Vó Olívia é possível perceber a essência das mulheres retratadas por Esmeralda, que nada se assemelham as mulheres de Lima Barreto. A personagem Clara dos Anjos é descrita por seu criador como romântica, sonhadora, frágil, superprotegida pelos pais, entre outras características das moças do início do século 20. Prendada, sabia cozinhar, bordar e costurar, além de receber lições de música. Uma personagem totalmente apática e facilmente manipulável. Dona Engrácia, mãe de Clara e responsável por sua educação, assemelha-se à filha. na apatia e na fragilidade. Tais mulheres são aquelas que Lima Barreto escolhera para representar as mulheres negras brasileiras na época. Diante disso, torna-se fácil perceber a indignação de Esmeralda ao ler o romance e não se identificar em nada com as personagens apresentadas.

\footnotetext{
${ }^{22}$ BARRETO. Clara dos Anjos, p. 133.
} 
O contrário das mulheres de Lima, são as de Esmeralda Ribeiro, estas sim, muitas leitoras se identificariam. Mulheres fortes, pois a fragilidade não compete às mulheres herdeiras de um passado de escravidão e exploração sexual, livres, imponentes, pois sempre tiveram que batalhar, tomar decisões, nunca aprenderam a cuidar de suas casas ou esperar que o esposo lhe provesse as coisas, mas a cuidar das casas das patroas, para que, por meio desse trabalho, pudesse prover sua sobrevivência. Estas sim são as mulheres negras de nossa sociedade e é para elas que Esmeralda escreve o conto, e sua protagonista partilha esse segredo. Pois elas saberiam entender sua atitude, visto que comungam das mesmas angústias.

Ao propor uma nova “Clara dos Anjos”, Esmeralda quebra com a estereotipia a que estava vinculada a representação das mulheres negras em nossa sociedade e propõe uma nova. Sobre esse tema, escreveu Leda Maria Martins, em seu artigo "O feminino corpo da negrura": 23

Quebrar os ritos de ficcionalização da mulher negra, tecer outras dobras, desdobrar seus contornos e alinhavos, ferir as imagens viciadas são atos performados por estes textos, que desvelam, na rasura dos véus da tradição poética e ficcional, outras possíveis silhuetas do feminino corpo da negrura.

\section{CONSIDERAÇÕES FINAIS}

Reescrever Clara dos Anjos constituiu uma atitude interessante e ousada de Esmeralda Ribeiro, pois, ao propor um novo desfecho para o drama barretiano, a leitora manifesta sua opinião a respeito do romance do seu antecessor, tornando-se escritora também. Nesse movimento de reescrita, a autora retoma a obra de Lima Barreto e coloca em discussão o papel da mulher negra em nossa sociedade e propõe, assim, um novo modelo de sua representação em nossa literatura.

O modelo apresentado em 1991, por meio do conto “Guarde segredo”, publicado na coleção Cadernos Negros do grupo Quilombhoje, representou uma reviravolta não só no que estava começando a se firmar no campo literário como literatura afro-brasileira, mas também no que se passou a compreender como literatura afro-feminina, ou seja, literatura escrita por mulheres negras para mulheres negras, visto que o assassinato de Cassi Jones, no conto de Esmeralda, significou uma resposta das mulheres negras ao modelo de representação a que foram submetidas durante esses anos na literatura brasileira, não só por Lima Barreto, mas por vários outros escritores, como Jorge Amado, Graciliano Ramos, Aluísio de Azevedo, entre outros. Tal resposta não correspondia ao horizonte de expectativa da época, visto que o

\footnotetext{
${ }^{23}$ MARTINS. O feminino corpo da negrura, p. 5.
} 
público estava acostumado ao modelo proposto por Lima Barreto e aos demais escritores citados acima. Nesse sentido, Jauss ${ }^{24}$ entende esse afastamento, ou não coincidência entre o horizonte de expectativa do público e o suscitado, por uma nova obra, como distância estética:

Assim, se a distância estética entre o horizonte de expectativa do público e o da obra é pequena, ou seja, se a obra atende, acomoda-se ao horizonte de expectativa do público, ela se aproxima do que Jauss chama de arte "culinária" ou ligeira. Seria o caso dos best-sellers, dos romances femininos de banca de jornal, cujas convenções ou sistemas literários de referência não se alteram. Ao contrário, se a distância estética entre os horizontes de expectativa (do público e da obra) aumenta, seu valor estético tende a ser maior, transformando, normalmente, as peculiaridades desse novo modelo num novo sistema literário de referência. ${ }^{25}$

Eagleton $^{26}$ também aborda a questão do valor da obra em seu texto, citando as ideias de Iser:

Para Iser, a obra literária mais eficiente é aquela que força o leitor a uma nova consciência crítica de seus códigos e expectativas habituais. A obra interroga e transforma as crenças implícitas com as quais a abordamos, "desconfirma" nossos hábitos rotineiros de percepção e com isso nos força a reconhecê-los, pela primeira vez, como realmente são. Em lugar de simplesmente reforçar as percepções que temos, a obra literária, quando valiosa, violenta ou transgride esses modos normativos de ver e com isso nos ensina novos códigos de entendimento.

Diante disso, se anteriormente dissemos que Lima Barreto inaugurou um novo horizonte ao escrever Clara dos Anjos, agora podemos dizer que Esmeralda Ribeiro inaugura um outro, ao reescrevê-lo. Podemos confirmar tal afirmação por meio do crescente número de publicações afro-femininas que emergiram nos últimos vinte anos, que nada mais são do que respostas de leitoras descontes com a bibliografia brasileira disponível e resolveram tornar-se escritoras, como forma de resistência e luta contra a manutenção da estereotipia na representação da mulher negra.

\section{RESUMÉ}

Cet article prétend analiser le papier du lecteur dans la critique littéraire moderne, chercher refléchir sur l'experience d’un lecteur spécifique: la femme noire brésilienne. Pour cet analyse, nous ferons une comparaison

\footnotetext{
${ }^{24}$ JAUSS. A história da literatura como provocação à teoria literária[0].

${ }^{25}$ ZAPPONE. Estética da recepção[0], p. 195.

${ }^{26}$ EAGLETON. Teoria da literatura: uma introdução[0], p. 119-120.
} 
entre les textes Clara dos Anjos, de Lima Barreto, et “Guarde segredo”, de Esmeralda Ribeiro.

\section{MOTS-CLÉS}

Lectrice, femme noire brésilienne, Clara dos Anjos, "Guarde segredo”

\section{REFERÊNCIAS}

BARRETO, Lima. Clara dos Anjos. São Paulo: Ática, 2003.

BONNICI, Thomas. Teoria e crítica pós-colonialistas. In: BONNICI, Thomas; ZOLIN, Lúcia Osana (Org.). Teoria Literária: abordagens históricas e tendências. 3. ed. rev. e ampl. Maringá: Eduem, 2009. p. 257-285.

BOSI, Alfredo. História concisa da literatura brasileira. São Paulo: Cultrix, 1999.

CARNEIRO, Sueli. Enegrecer o feminismo: a situação da mulher negra na América Latina a partir de uma perspectiva de gênero. Disponível em: <http://www.unifem.org.br/sites/700/710/00000690.pdf>. Acesso em: 22 jun. 2011.

EAGLETON, Terry. Teoria da literatura: uma introdução. Trad. Waltensir Dutra. 6. ed. São Paulo: Martins Fontes, 2006.

FIGUEIREDO, Maria do Carmo Lanna. A atualidade da obra de Lima Barreto. In: FIGUEIREDO, Maria do Carmo Lanna; FONSECA, Maria Nazareth Soares (Org.). Poéticas afro-brasileiras. Belo Horizonte: Mazza/PUC Minas, 2002. p. 133-157.

JAUSS, Hans Robert. A história da literatura como provocação à teoria literária.Trad. Sérgio Tellaroli São Paulo: Ática, 1994.

LIMA, Marcos Hidemi de. Pobre, mulata, mulher: a estigmatização de Clara dos Anjos. Disponível em: <http://www.letras.ufmg.br/literafro/frame.htm>. Acesso em: 19 jun. 2011

MARTINS, Leda Maria. O feminino corpo da negrura. Revista de Estudos de Literatura. Belo Horizonte, p. 111-121, 4 out. 1996.

NEVES, José Eugênio das. Esmeralda Ribeiro e Lima Barreto: um diálogo sem segredos. Terra Roxa e outras terras - Revista de Estudos Literários, Londrina, 17-b, p. 49-59, dez. 2009.

RIBEIRO, Esmeralda. Guarde segredo. In: Vários Autores. Cadernos Negros 14, contos. São Paulo: Quilombhoje, 1991. p. 23-30.

ZAPPONE, Mirian Hisae Yaegashi. Estética da recepção. In: BONNICI, Thomas; ZOLIN, Lúcia Osana (Org.). Teoria Literária: abordagens históricas e tendências. 3 ed.rev. e ampl. Maringá: Eduem, 2009. p. 189-199. 